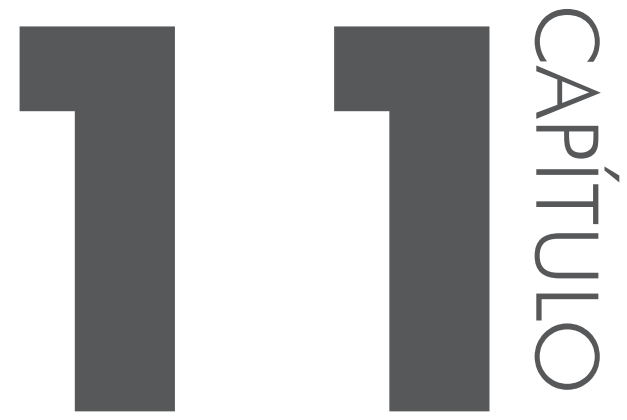

\title{
A SEGREGAC̣ÃO ESPACIAL E RESIDENCIAL NA CIDADE CONTEMPORÂNEA
}

Douglas Parreira Santos Idelvone Mendes Ferreira

Resumo: O presente trabalho buscou desenvolver uma discussão teórica sobre a segregação socioespacial na cidade contemporânea, baseando-se na pesquisa de mestrado que está sendo desenvolvida na cidade de Franca-SP. Foram utilizados autores que abordam a temática dentro da Geografia Urbana, além de outros cientistas sociais que enriquecem o discurso da desigualdade no espaço urbano e consequentemente residencial. Apesar de ser um conceito muito utilizado na ciência geográfica, o termo segregação ainda carece de definições mais precisas para ser utilizado da forma correta. Para suprir essa necessidade, foi desenvolvida uma discussão sobre o conceito, a fim de facilitar o seu entendimento. A segregação socioespacial nas cidades hoje é causada pelos agentes que vivem no espaço urbano, desde os dominantes até os excluídos. Essa segregação pode ser vista principalmente na estrutura das cidades e no modo como elas se transformam 
para se adequar às tendências do mercado. Isso resulta na segregação residencial totalmente visível nas cidades contemporâneas. Conforme as cidades crescem, aumentam os índices de violência e a segurança torna-se uma mercadoria. Dessa forma, o aumento da incidência de prédios e condomínios fechados nas cidades pode ser visto como fuga desses problemas sociais.

Palavras-chave: Segregação espacial. Segregação residencial. Segregação socioespacial. Desigualdade.

Abstract: This study sought to develop a theoretical discussion of the sociospatial segregation in the contemporary city. Authors were used to address the issue within the Urban Geography, among other social scientists that enrich the inequality of speech in urban areas and consequently residential. Despite being a concept widely used in geographical science segregation still needs more precise definitions to be used the right way to meet this need a discussion on the concept of segregation was developed in order to facilitate understanding of it. The socio-spatial segregation in cities today is caused by various agents who live in urban areas, from the dominant to the excluded. This segregation can be seen mainly in the structure of cities and how they are transformed to suit market trends. This results in fully visible residential segregation in contemporary cities. As cities grow, they increase the levels of violence and security becomes a commodity, thereby increasing the incidence of buildings and condominiums in cities as an escape for these social problems.

Keywords: Spatial segregation. Residential segregation. Socio-spatial segregation. Inequality.

\section{INTRODUC̣ÃO}

Foco de grandes debates nas ciências sociais, a segregação é um conceito que, apesar de apresentar uma gama de possibilidades de estudos e pesquisas dentro das cidades, ainda carece de conceituação adequada. Na Geografia dentro da Geografia Urbana, vários autores discutem esse conceito no âmbito de cidades, principalmente de metrópoles como São Paulo e Rio de Janeiro. No Brasil, ainda estamos carentes de estudos sobre segregação em cidades médias, onde, segundo alguns poucos autores que discutem o tema, já é forte a incidência da segregação.

A segregação socioespacial nas cidades se dá a partir da relação entre os agentes produtores do espaço urbano. Esses agentes podem ser dominantes (Estado, produtores imobiliários etc.) ou agentes sociais excluídos que também contribuem para a produção do espaço urbano.

Pode-se observar a segregação socioespacial na configuração das cidades contemporâneas, observando-se favelas, cortiços, centros deteriorados, condomí- 
nios fechados, prédios e áreas residenciais. A cada ano aumenta a incidência de condomínios fechados nas cidades, esse fato se dá pelo aumento da população da cidade e com isso o agravamento de alguns problemas sociais como segurança e violência. Esses fatores contribuem para o aumento de condomínios fechados nas cidades, pois os produtores imobiliários veem nesse problema social uma fonte de renda ao usarem a segurança como principal mercadoria para venda de moradias.

Surge assim a segregação residencial: pessoas segregam outras pessoas, pois moram em realidades bem diferentes umas das outras, como se existissem várias microcidades dentro da cidade. Este trabalho tem como finalidade discutir essas temáticas dentro da Geografia Urbana, enfatizando a segregação residencial presente nas cidades contemporâneas.

A discussão apresentada é parte de resultados preliminares da pesquisa que está sendo desenvolvida na cidade de Franca-SP.

\section{SEGREGAC̣ÃO: CONCEITOS E DEFINIC̣ÕES}

Para adentrarmos as discussões sobre a segregação socioespacial e residencial, é necessário em primeira instancia que entendamos o significado do conceito de segregação, embasado nas definições da Geografia Urbana.

A segregação socioespacial é originária das relações entre os agentes produtores do espaço urbano. Uma vez que o sistema capitalista beneficia os indivíduos que possuem maior poder aquisitivo, os de renda inferior são obrigados a habitarem locais desapropriados ou são constantemente remanejados para outras áreas, a fim de "esconder" essas moradias. Apesar do sistema atual estar munido de diversas formas de domínio e segregação na cidade, é na segregação socioespacial, fruto da produção do espaço urbano, que essas formas podem ser vistas claramente, dando subsídios para análise e crítica.

Segundo o dicionário Aurélio (2000), a palavra segregação se define como: a) ato de segregar e b) tratamento desigual ou injusto dado a uma pessoa, com base em preconceitos de alguma ordem, notadamente sexual, religioso, étnico etc. Entende-se portanto que o ato de segregar é relacionado ao ato de exclusão, praticado de diversas formas, no contexto das segregações residencial, social e espacial. Partindo para as definições clássicas, Vasconcellos (2013) discorre que o termo segregação é um dos mais discutidos dentro das ciências sociais.

A origem histórica do termo se deu com a construção de um gueto em Veneza, em 1516 (WIRTH, 1980), com o intuito de separar os judeus da população. Ainda sobre os guetos, Marcuse (2006) explana que segregação é um processo de formação e manutenção do gueto, o qual é uma área involuntariamente concentrada espacialmente e usada pela sociedade dominante para separar e limitar 
um grupo particular da população, externamente definida por uma característica racial, étnica, ou, ainda, financeira.

É importante ressaltar aqui que, segundo Wacquant (2008) e Vasconcellos (2004), essa conceituação de gueto como área segregada em Veneza não pode ser comparada com as favelas e cortiços, pois esses são reflexos de bairros operários, ou seja, os indivíduos têm liberdade de entrarem ou saírem do local, podendo se mudar para uma área mais nobre, de acordo com a sua renda.

Para Sposito (2013, p. 64-65), “segregação seria sinônimo ou expressão de qualquer forma de diferenciação ou desigualdade nas cidades". A autora discorda do termo, por haver imprecisão e diminuição da força explicativa do conceito. Concorda-se com a autora que a segregação vai além das desigualdades nas cidades e que o conceito só pode ser aplicado quando as formas de diferenciação levam a uma separação espacial radical e implicam rompimento, sempre relativo, entre a parte segregada e o conjunto do espaço urbano, dificultando as relações e articulações que movem a vida urbana.

A segregação espacial é parte integrante e fundamental da produção do espaço urbano. Essa temática ampla está longe de ser esgotada nos estudos geográficos e nas ciências sociais. Mas o termo necessita de um aprofundamento, pois as práticas sociais, assim como a configuração constante das cidades, nos mostram que existem questionamentos do passado e do presente que ainda não foram investigados a fundo. Apesar de a segregação ocorrer nas cidades, não se pode deixar de mencionar os conflitos raciais, religiosos, trabalhistas, políticos, econômicos e de classes já existentes nas cidades.

Desse modo, é imprescindível salientar que os processos de globalização, as mudanças na economia, a diminuição do papel do Estado, as migrações e os movimentos sociais são fatores que também redimensionam a cidade e criam novos conflitos, sem eliminar os já existentes.

A questão da segregação socioespacial, com ênfase à segregação residencial, é visivelmente a temática mais abordada entre os geógrafos que discutem a cidade e o urbano, pois esse fenômeno apresenta aspectos que dão subsídios para análise da realidade de várias cidades brasileiras. As residências nos dias atuais perderam sua essência de habitação, cuja importância fundamental era o construir para morar, pois a construção de casas para moradia nas cidades de hoje tornou-se um grande produto para o mercado. Com isso, a segregação urbana, que acontece em vários setores da cidade, pode ser observada mais claramente nesse aspecto (residencial).

A desigualdade espacial difundida nas cidades é fruto da desigualdade social, imposta pelo sistema vigente. Essa segregação não se percebe apenas nas diferenças de residências, mas também na renda real, na ausência ou má qualidade de 
serviços públicos como educação, transporte, saneamento básico (água tratada e encanada, coleta e tratamento de esgoto, ruas asfaltadas), coleta de lixo, infraestrutura social (escolas, creches, hospitais etc.). Com a segregação, os custos da cidade, como crime, violência, impactos ambientais, miséria, pobreza, ficam (de certa forma) distantes das classes dominantes. Complementando esse pensamento sobre a desigualdade na cidade, Maricato (2001, p. 51) comenta: "É impossível esperar que uma sociedade como a nossa, radicalmente desigual e autoritária, baseada em relações de privilégio e arbitrariedade, possa produzir cidades que não tenham essas características.”.

Sobre essa questão, Villaça (2001) comenta que uma das características das metrópoles brasileiras (também pode ser observada em cidades médias) é a segregação espacial dos bairros residenciais de distintas classes sociais. Atualmente são criados bairros, sítios sociais e áreas muito particulares onde a distinção de classes é visível. É importante ressaltar que, segundo Souza (2007), “o fenômeno da segregação residencial é universal e tão antiga quanto as cidades”, portanto, pode-se afirmar que não é caso específico das metrópoles e sim de um sistema de classes histórico culturalmente difundido na sociedade.

A segregação residencial acontece especialmente quanto à localização na cidade, que está relacionada intrinsecamente com a reprodução de força de trabalho. Dessa forma, a sociedade urbana transforma seletivamente os lugares, adaptando-os às suas necessidades de funcionamento. Observa-se aqui que não só as classes dominantes configuram e reconfiguram os espaços da cidade, os indivíduos com baixo poder de aquisição e os indivíduos segregados também transformam a cidade ao seu modo, criando moradias e se deslocando dentro da cidade em busca de melhores áreas (não ideais) para habitar.

A segregação residencial para Castells (1983) é o resultado, no espaço urbano, da necessidade de existências distintas entre grupos sociais. Dessa forma, as áreas segregadas estabelecem os locais da reprodução das diferentes classes sociais. Aprofundando o contexto, Harris (1984, p. 26) comenta sobre a segregação residencial e a segregação de classes:

A segregação das classes é um aspecto distintivo da cidade capitalista [...] Historicamente [...] apareceu em sua forma atual somente a separação entre lugar de trabalho e residência, criando as condições para o desenvolvimento de um específico mercado de habitação que se tornou o mecanismo pelo qual as relações de classe no novo sistema de produção industrial fosse refletido no espaço residencial urbano.

Concorda-se com o autor que a questão da segregação, no âmbito de classes e residencial, é histórica e culturalmente diluída na sociedade. Essa exclusão de grupos e classes sociais dentro do urbano, para Lefebvre (2008, p. 32), é uma 
exclusão também da sociedade: "excluir do urbano, classes, indivíduos, implica também excluí-los da civilização, até mesmo da sociedade. O direito à cidade legitima a recusa de se deixar afastar da realidade urbana por uma organização discriminatória, segregadora”.

É notório nas cidades brasileiras que a segregação residencial divide as classes sociais dentro de seus muros. O mercado imobiliário viu nas residências uma fonte lucrativa de renda, e morar não é mais um direito, e sim um produto. Quem tem maior poder aquisitivo, fica com o melhor produto. Áreas residenciais, prédios, condomínios fechados, todos esses empreendimentos são habitações segregadoras. O problema principal é que o Estado, junto ao mercado imobiliário, impõe condições para que os indivíduos que os habitam também se tornem segregadores. A falta de segurança, a violência, a criminalidade, a pobreza, a miséria viraram discurso de venda de imóveis. A precarização de infraestrutura urbana oferecida pelo Estado aliada às abusivas e sedutoras propagandas de habitações do mercado imobiliário criam uma sociedade cada vez mais separatista.

Obviamente, habitar condomínios fechados e prédios com segurança 24 horas, cerca elétrica, muros altos e sistemas de alarmes são opções da população preocupada com segurança e bem-estar. Mas esse fator também agrava a segregação residencial, uma vez que nem todos têm possibilidades de habitar esses locais. Como o Estado é refém da economia neoliberal, a precarização de algumas áreas e a renovação urbana serão incessantemente cultivadas pelo mercado imobiliário, gerando a "gentrificação".

Gentrificação (do inglês gentry: baixa nobreza) urbana é a "restauração" da propriedade urbana deteriorada, especialmente em bairros populares, pelas classes média e alta, mas é ainda uma elitização espacial dessas áreas. Smith e Williams sintetizam o termo dizendo: "Como a terminologia sugere, 'gentrificação' conota um processo que opera o mercado imobiliário residencial. Ele se refere à reabilitação de habitações populares ou abandonadas e a subsequente transformação de uma área em um bairro de classe média." (SMITH; WILLIAMS,1989, p. 96-120 apud SOUZA, 2013, p. 134).

Ora, se o processo de gentrificação está aliado ao mercado imobiliário, pode-se afirmar que esse está vinculado diretamente ao capitalismo e ao Estado, o que torna mais problemático o processo de segregação socioespacial. Quando uma dada área desperta interesse de um desses agentes, começa-se um processo de análise financeira sobre a porção de terra urbana do local. Nem sempre essas áreas são áreas nobres. Esses locais podem ser cortiços, favelas ou prédios deteriorados do centro, dos subúrbios ou das periferias. Quando eles são comprados por novos agentes, seria necessário que se fizesse uma realocação correta e planejada dos indivíduos que já habitavam essa área, o que raramente acontece. 
A expansão do urbano no ritmo acelerado das cidades contemporâneas é tamanha que áreas afastadas e sem valor de mercado começaram a serem utilizadas pelo mercado imobiliário e pelo Estado a fim de obterem mais renda sobre a terra urbana. A gentrificação dessas áreas que recebem um upgrade visual, financeiro e estrutural é feita para despertar o interesse de classes mais favorecidas. Sobre essa questão Jacobs $(1973$, p. 18) completa: "É completamente inútil planejar a aparência de cidade (isto é, seu aspecto exterior) ou especular sobre a melhor maneira de lhe dar uma aparência de ordem sem conhecer antes seu funcionamento e ordem reais. Limitar-se à simples aparência das coisas e considerar essa aparência o propósito principal ou o fundo do problema redunda em prejuízo completo do que se quer fazer”.

O autor chama a atenção para as questões sociais de se planejar o urbano, pois enquanto os agentes dominantes tiverem a aparência da cidade como foco principal de suas ações, a cidade continuará perdendo a sua essência, deixando de ser "o que realmente é" para parecer "o que querem fazer parecer", o que agrava as questões socioespaciais na cidade. A periferização de áreas e o embelezamento de outras (gentrificação) também são ações segregadoras do espaço urbano.

Outro problema recente das cidades contemporâneas causado pela periferização advinda dos processos de produção dos agentes dominantes do espaço urbano é a "autossegregação". Basicamente esse fenômeno ocorre quando os indivíduos das classes sociais de alto poder aquisitivo agrupam-se em condomínios fechados, prédios e residenciais afastados dos centros, ou seja, afastados da aglomeração da cidade, da pobreza, miséria, violência, criminalidade e falta de estrutura.

Esses espaços habitacionais se tornaram objetos de desejo imobiliário e, dessa forma, despertaram o interesse dos agentes imobiliários. Hoje, é possível encontrar condomínios fechados voltados para a classe média e casas mais modestas que vendem o mesmo produto que os condomínios das classes altas, isto é, afastamento de centros, segurança etc. Desse modo, o problema da segregação socioespacial nas cidades ganha uma nova vertente ao se criarem novas "cidades" dentro da cidade. Esses condomínios são isolados fisicamente do centro principal da cidade, mas suas construções são planejadas para oferecerem infraestrutura ideal para os indivíduos que habitam esses locais. Concernente a esta questão, Santos argumenta que:

Projetou-se e criou-se um novo espaço. Não foi colocado à venda só o terreno, mas um novo estilo de vida, uma maneira moderna de morar, a valorização do verde, o contato com a natureza, a segurança entremuros, deixando-se para trás a poluição, a violência, o corre-corre, a desordem urbana. O condomínio fechado surgia como uma nova concepção de morar numa cidade marcada pela insegurança. (SANTOS, 1994, p. 277). 
São construídos parques, vias de acesso, escolas, comércios etc. que favorecem os indivíduos que moram nesses locais e os previnem de se deslocarem constantemente para o centro principal da cidade quando forem consumir. Isso beneficia também os proprietários imobiliários que veem essas estruturas como meios de propaganda e de aumento do valor da terra urbana no local.

Diferentemente da Centralidade, as Áreas Centrais da cidade são representadas por aglomerações de atividades comerciais ou de serviços. Empiricamente, elas podem ser apreendidas, posto se que trabalha nelas, passeia-se por elas, senta-se em suas praças e participa-se de atividades que nelas são desenvolvidas. Essas áreas, portanto, são espaços que ancoram a constituição das centralidades, mas não é a mesma coisa. Assim, a multiplicação das áreas que concentram atividades comerciais e de serviços revela-se por meio da nova espacialização urbana, o que permite identificar o conceito de Centro. Dessa forma,

[...] não há centro sem que se revele sua centralidade, assim como essa centralidade não se expressa sem que uma concentração se estruture. Se o centro se revela pelo que se localiza no território, a centralidade é desvelada pelo que movimenta no território, relacionando a compreensão da centralidade, no plano conceitual, prevalentemente à dimensão temporal da realidade. O que é central é redefinido em escalas temporais de médio e longo prazo pela mudança na localização territorial das atividades. A centralidade é redefinida continuamente, inclusive em escalas temporais de curto prazo, pelos fluxos que desenham através da circulação de pessoas, das mercadorias, das informações, das ideias e dos valores. (SPOSITO, 2001, p. 238, grifos da autora).

Outros conceitos que surgem nessa espacialização de diferentes áreas centrais dentro da cidade são a Multicentralidade e a Policentralidade. Essencialmente, a Multicentralidade é a criação de mais de uma área de concentração comercial e de serviços nas cidades, o que leva (de certo modo) à perda relativa do peso da importância do centro principal. A Policentralidade, por sua vez, não é definida por todas as áreas centrais, mas por hipermercados, shopping centers, centros especializados de grande porte como: negócios, serviços, feiras, entre outros.

Esses conceitos se distinguem dos anteriores por três razões: primeiramente, por exercerem atração para toda a cidade, diferentemente de pequenos centros ou galerias de prédios. Em segundo, não resultam de uma somatória de iniciativas de comerciantes, do Estado, de prestadores de serviços PPPs (Parcerias Público-Privadas), entre outras atividades. São grandes áreas comerciais ou de serviços devidamente e previamente planejadas, construídas e ocupadas em um curto período de tempo, com o intuito de começarem suas atividades em menor tempo. Relacionado a esse tipo de empreendimento, Souza fala sobre o planejamento de facilitação que 
[...] representa um grau a mais na escala de mercadofilia: longe de apenas acompanhar e tentar mimetizar (camuflar) o mercado, aqui o planejamento serve para estimular a iniciativa privada, oferecendo-lhes numerosas vantagens e regalias, de isenções tributárias a terrenos e infraestrutura subsidiados, de informações vitais à suspensão ou abolição de restrições de uso impostas por zoneamentos para determinadas áreas (SOUZA, 2011, p. 11).

Em terceiro lugar (e ponto chave do processo), esses empreendimentos geram segmentação e seletividade socioespaciais, as quais, em alguns casos, chegam a ser condicionantes do processo de segregação socioespacial nas cidades, visto que reforçam a estrutura de separação social do uso residencial no espaço urbano.

Destarte, poder-se-ia concluir que essas áreas centrais podem ser saudáveis para a manutenção da cidade ao propiciarem um "esvaziamento" do centro principal com a criação de subcentros de comércios e de serviços. Contudo, tais áreas agravam a segregação socioespacial; em primeiro lugar, por estarem afastadas da malha urbana central, onde se concentra o maior número de pessoas da cidade e, em segundo, por oferecerem serviços que, às vezes, não são voltados para toda a população da cidade, mas para uma determinada classe ou grupo.

Nesse contexto, Domingues disserta:

Durante os séculos a cidade teve o monopólio da infraestrutura, necessária à edificação e à organização urbana. Hoje a infraestrutura percorre territórios imensos facilitando um processo de colonização urbana onde o edificado se conecta diretamente com a estrada. Ao contrário da cidade, o território urbano é um “exterior”, uma nebulosa, uma mancha extensiva e diversa que tudo mistura em densidade e diversidade formal e funcional (DOMINGUES, 2009, p. 17).

Via de regra, é correto afirmar que as estratégias do mercado para as habitações são ilimitadas, tendo em vista que a cada época mudam-se as tendências da cidade, bem como seus fluxos, formas e valores. Com isso, os agentes e as classes sociais dominantes acompanham essa reestruturação mercadológica imobiliária, fazendo com que haja uma constante (re)configuração do/no espaço urbano.

Os processos de produção do espaço urbano pelos agentes dominantes geram a segregação socioespacial nas cidades. A verdade é que o espaço urbano necessita de uma intervenção estrutural, ou seja, um planejamento adequado para os processos que o integram. A desarticulação estrutural nas cidades é efeito de um mau planejamento ou do não planejamento.

Os processos de (re)configuração do espaço urbano acontecem e se solidificam por impulso dos agentes dominantes, pela pressão da economia e/ou do mercado. O olhar perverso sobre uma área, visando retirar daquela porção de terra urbana o máximo de lucro possível, ignora todos os demais elementos desse 
local. Antigas estruturas, centros, prédios históricos, construções que contam a história das cidades, que trazem um resgate histórico do local, são simplesmente ignorados por esses agentes. Obras vistas apenas como empilhados de tijolos e concreto que, por hora, são um obstáculo, mas que, futuramente, serão fonte de renda e darão lugar a grandes estruturas como prédios, condomínios fechados, supermercados e/ou comércios. Construções que, diferentemente das que ali estavam, compõem-se de cores, formas, estrutura de ferro e aço e de um aparato de microelementos que expressam as tendências do mercado e do sistema.

Via de regra, o Estado tende a privilegiar os interesses das classes dominantes que, por ora, estão no poder. Como agente produtor do espaço urbano, o Estado cria condições para a reprodução da sociedade capitalista. Seja por incentivos fiscais, pela doação de terras do urbano, pela criação/alteração de leis habitacionais ou pelo uso do solo urbano, o Estado sempre irá beneficiar as classes sociais dominantes, de modo que, não diferentemente dos agentes discutidos anteriormente, agrava a segregação socioespacial.

A complexidade da ação dos agentes no urbano abrange uma gama de elementos que fazem com que o espaço urbano esteja em constante mutação e passe por uma organização/reorganização reproduzida das relações capitalistas e sociais. São exemplos de reorganização espacial: densificação do uso do solo, deterioração de determinadas áreas, renovação urbana, relocação diferenciada da infraestrutura, transformação das terras agrícolas em terras urbanas, deslocamento de setores e células urbanas.

Os grandes proprietários e empresários comerciais são grandes consumidores do espaço, portanto, necessitam de terrenos amplos e baratos para que, assim, alcancem a acumulação do capital. Dessa forma, o solo urbano tem duas vertentes, a de suporte físico, abarcando toda a área da empresa, sem limitações e a de proporcionar requisitos locacionais específicos para as atividades a serem desempenhadas no local. São exemplos: ferrovias, rodovias, aeroportos, hidrovias próximas (escoamento de produtos) que facilitam a acessibilidade para a população consumidora (comércio).

As relações entre os proprietários dos meios de produção e do solo urbano são complexas. Os detentores do solo urbano aumentam o preço dos lotes de terra com a finalidade de obterem lucro. As empresas, por sua vez, fazem pressão para que os lotes de terra se tornem mais acessíveis financeiramente para também obterem mais lucros, visto que, assim, terão menos despesas com a construção e a manutenção de empresas, comércios e empreendimentos. Nesse embate, entram, ainda, os trabalhadores que cobram salários mais altos por não terem acessibilidade e infraestrutura habitacional, o que os obriga a se deslocar diariamente para o trabalho. 
Esses conflitos tendem a ter resultados positivos para os proprietários dos meios de produção, que comandam a vida econômica e política por meio do Estado que desapropria lotes de terra, cria infraestrutura e oferece benefícios como redução ou isenção de taxas e impostos, concessão de lotes de propriedades públicas para construção e ampliação das empresas e, geralmente, baixa fiscalização, inclusive ambiental. Dessa forma, cria-se o que Marx (1988) chama de "superpopulação relativa”. Ela constitui um exército industrial de reserva disponível, que pertence ao capital de maneira tão absoluta como se este o tivesse criado à sua própria custa:

O curso de vida característico da indústria moderna, sob a forma de um ciclo decenal, interrompido por oscilações menores, de vitalidade média, produção a todo vapor, crise e estagnação, repousa na contínua constituição, na maior ou menor absorção e na reconstituição do exército industrial de reserva ou superpopulação. Por sua vez, as oscilações do ciclo industrial recrutam a superpopulação e tornam-se os mais enérgicos agentes de sua reprodução. (MARX, 1988, p. 192).

Sobre o exército reserva, criado no sistema capitalista e que diminui a luta de classes e os direitos dos trabalhadores, Castel completa:

“Foi a relação com o trabalho que mudou profundamente. Ele é daqui para frente
vivido por muitos como inquietação. O medo de perder o emprego predomina [...]
Mas, é ainda sobre o trabalho, quer se o tenha, quer este falte, quer seja precário ou
garantido, que continua a desenrolar-se, hoje em dia, o destino da grande maioria
dos atores sociais." (CASTEL, 1998, p. 157).

Os proprietários de terras atuam no sentido de obterem maior renda fundiária de suas propriedades, para que estas gerem maior lucro possível. Preocupam-se, também, com a conversão da terra rural em terra urbana, ou seja, com a expansão dos espaços da cidade, visto que as terras do urbano são mais valorizadas que as do rural.

Não menos importantes, os grupos sociais excluídos também são agentes produtores do espaço urbano. Grande parcela da população não tem condições de arcar (comprar ou alugar) com uma moradia digna. Tal fato é reflexo do sistema vigente. A segregação que acontece em nossa sociedade se dá de diferentes formas: social, trabalhista, religiosa ou cultural. Entretanto, é na segregação espacial que se pode observar mais nitidamente esse fenômeno.

$\mathrm{Na}$ cidade contemporânea, a possibilidade de se possuir uma moradia decente para esses grupos é quase nula - o que leva esses agentes a ocuparem cortiços superpopulosos localizados nos centros da cidade, residências velhas, esqueletos de edifícios, residências construídas pelo Estado, geralmente, sem infraestrutura e de péssima localização, e favelas. Um exemplo de moradias deterioradas pode ser 
visto no Bairro Vila Gosuen, em Franca-SP, bairro com altos índices de criminalidade, violência e tráfico de drogas.

É nas favelas, nesses bairros com casas deterioradas, na ocupação de terrenos públicos e privados que esses agentes transformam o espaço atuando como "modeladores" ao produzirem seu próprio espaço e moradia. As ações de ocupação desses agentes são uma forma de resistência ao sistema capitalista segregador e, ao mesmo tempo, uma estratégia de sobrevivência. Vale ponderar que essas áreas ocupadas são, em sua maioria, terrenos inadequados e sem valor de mercado, como áreas alagadiças, encostas, morros e outros com problemas de ordem física.

Dessa forma, os proprietários fundiários exercem pressão sobre o Estado para que haja: a) valorização de suas terras por meio do investimento público e da infraestrutura (especialmente a viária) e b) definição/alteração das leis de uso e do zoneamento urbano. Vale ressaltar que essa pressão não acontece de forma integrada e não beneficia a todos os proprietários fundiários. Mesmo dentro da minoria dominante, existem conflitos de poder e de interesses, fazendo com que os proprietários e o Estado atuem de forma singular para obterem seus próprios resultados.

Apesar da grande pressão dos proprietários fundiários nas zonas periféricas da cidade, a passagem da terra agrícola para a terra urbana é complexa. As demandas dessas terras dependem dos fluxos migratórios da cidade, bem como requerem que os migrantes detenham um nível de renda favorável que lhes possibilitem participar do mercado de terras e habitações.

As formas de ocupação dessas terras são: a) a urbanização de status e b) a urbanização popular. As estratégias dos proprietários fundiários para estas terras variam conforme a especulação. Os proprietários de terras bem localizadas, ou seja, que abrangem valores físicos, como mar, lago, matas, proximidade de centros comerciais, localização, pressionam o Estado por investimentos nessas áreas para tornarem-nas mais lucrativas. Essas terras "periféricas" da cidade são voltadas para a população de status mais elevado. Prédios, condomínios fechados e conjuntos habitacionais camuflam a ideia de periférico, a qual passa a ser discriminada pela questão social (divisão de classes) e não pela estrutural.

Em segundo lugar, os proprietários de terras mal localizadas, em periferias sem valores físicos, conquanto não tenham grandes lucros como os proprietários de terras valiosas, constroem loteamentos populares em suas terras, a fim de captar renda. De ordinário, esses loteamentos são construídos sem nenhuma infraestrutura e são erguidos ou pelo sistema de autoconstrução, que tem como objetivo contribuir para a racionalização da construção popular, desde a concepção de projetos até a execução das construções, ou pelo Estado com iniciativas como o programa Minha Casa, Minha Vida, cujo público-alvo são as famílias de baixa renda. 
Vale falar ainda dos indivíduos que são constantemente expulsos dessas áreas, que têm ali o único teto para abrigar a sua família, que sofrem pressão do Estado por intervenção jurídica e, até mesmo, por força policial; que não têm leis nem políticos que apoiem suas lutas dentro das cidades e que cobram o direito de morar e não são ouvidos.

Esses sujeitos habitantes desses locais, os quais encontram-se muitas vezes sem trabalho, são indigentes, pais de família, crianças, idosos, que, infelizmente, aos olhos dos agentes dominantes da cidade, são vistos como as edificações antigas, isto é, considerados apenas obstáculos. São uma obstrução temporária de carne e osso, sem vida, sem história e sem importância, que impede (temporariamente) as necessidades e interesses desses agentes, mas que será, assim como as obras antigas, demolida (socialmente) e esquecida. Esse é o cotidiano do espaço urbano brasileiro.

\section{RESULTADOS PELIMINARES E CONCLUSÕES}

Esse trabalho buscou desenvolver uma discussão sobre a segregação urbana, socioespacial e residencial nas cidades brasileiras por meio da pesquisa que está sendo desenvolvida na cidade de Franca-SP. É importante ressaltar que a falta de estudos nas cidades médias também proporciona a inflamação dos problemas sociais na cidade. Esse levantamento teórico preliminar foi de extrema importância para a continuidade da pesquisa. Segundo o Instituto Brasileiro de Geografia e Estatística (IBGE), a cidade de Franca-SP tem uma estimativa de 339.461 habitantes, fazendo com que seja classificada como uma cidade média.

Por vezes, estudamos grandes metrópoles, onde a incidência de problemas sociais são mais elevados e nos esquecemos que, em outras cidades de menor porte, esses problemas também existem. A segregação residencial é realidade nessas cidades, a cada ano são construídas mais moradias em condomínios não só para a classe alta da sociedade, mas para a média também, que conseguiu nos últimos anos um poder de compra mais elevado. Durante a pesquisa pode-se constatar a segregação socioespacial e residencial no objeto de estudo. Enquanto, em algumas áreas da cidade, notamos o aumento de condomínios fechados, prédios etc., em outras áreas, vemos casebres e moradias deterioradas. Na Vila Gosuen, conhecida como "Puxa Faca", foram construídas moradias para a população que vivia na favela do bairro Aeroporto, sem sucesso.

Hoje o bairro é um dos mais perigosos de Franca-SP, com altos índices de violência, de criminalidade e de tráfico de drogas. Por enquanto, não foi possível fotografar a área, justamente pelo perigo de se atravessar o bairro mesmo em veículos. Policiais militares só adentram o bairro em comboio e fortemente armados para procurar drogas e localizar traficantes. Outro problema é a configu- 
ração do bairro: assim que a polícia é avistada, há uma certa “debandada” dos moradores para dentro de suas residências, o que torna às vezes sem sucesso a procura dos policiais por traficantes. Os casebres, na maioria das vezes, são todos interligados, com várias entradas, saídas e portas falsas, como um labirinto, o que dificulta ainda mais os procedimentos dos policiais.

No decorrer da pesquisa o bairro será fotografado a fim de mostrar as moradias deterioradas para ilustrar que o esforço da prefeitura em mover a população da favela de um bairro para o outro, apenas mudou a criminalidade de local. Ainda na pesquisa será feita uma comparação entre os tipos de segregação existentes na cidade média: por um lado, os condomínios fechados, prédios residenciais etc e, por outro, os bairros que contemplam favelas, casebres e que tenham alto índice de criminalidade. Essas duas formas de segregação na cidade de Franca-SP, são ocasionadas principalmente por políticas públicas devido a três fatores:, o primeiro é por promover cada vez mais a construção de moradias "muradas"; o segundo, por não considerar a segurança pública como fator importante no desenvolvimento da sociedade; e o terceiro, por criar políticas de moradias insustentáveis.

Os estudos nas ciências sociais devem se pautar pelos tipos de segregação existentes dentro do território das cidades, pois o acúmulo de condomínios e residenciais murados e com segurança 24 horas pode se tornar um problema em alguns anos. A estrutura que abrange esses condomínios nos dias atuais sugere que em alguns anos poderá ocorrer uma alteração no modelo.

Avenidas, estradas, pontos comerciais diversos, todos esses elementos integram uma área beneficiada pelos condomínios fechados. Dentro dos condomínios existem áreas de lazer e de convívio, que, de certa forma, separam os "murados" do restante da cidade, os quais só se relacionam em algumas ocasiões. Segundo alguns autores mais críticos, chegará uma hora que esses estabelecimentos comportarão creches, escolas e hospitais aumentando drasticamente a segregação urbana nas cidades.

A essência do homem como ser social, ou seja, que se relaciona, se perderá nessa estrutura segregadora contemporânea. Existirão cada vez mais microcidades dentro de uma cidade.

\section{REFERÊNCIAS}

CASTEL, R. As metamorfoses do trabalho. In: FIORI, J. L.; LOURENÇO, M. S.; NORONHA, J. C. (Org.). Globalização: o fato e o mito. Rio de Janeiro: Ed. UERJ, 1998, p.147-163.

CASTELLS, M. A questão urbana. 4. ed. Rio de Janeiro: Paz e Terra, 1983.

DOMINGUES, A. A rua da estrada. Porto: Dafne Editora, 2009. 
FERREIRA, A. B. de H. Miniaurélio século XXI: o minidicionário da língua portuguesa. Rio de Janeiro: Nova Fronteira, 2000.

HARRIS, R. Residential segregation and class formation in the capitalist city: a review and directions for research. Progress in human geograpy, n. 8, p. 26-49, jan. 1984.

JACOBS, J. Morte e vida de grandes cidades. São Paulo: Martins Fontes, 2000.

LEFEBVRE, H. Espaço e política. Tradução Margarida Maria de Andrade e Sérgio Martins. Belo Horizonte: UFMG, 2008.

MARCUSE, P. Of states and cities: the partioning of urban space. Oxford: Oxford University Press, 2006.

MARICATO, E. Brasil, cidades: alternativas para a crise urbana. Petrópolis: Vozes, 2001.

MARX, Karl. O Capital: crítica da economia política. Tradução Regis Barbosa e Flávio R. Kothe. 3. ed. São Paulo: Nova Cultural, 1988. v. 1.

SANTOS, M. A urbanização brasileira. São Paulo: Hucitec, 1994.

SOUZA, M. O. ABC do desenvolvimento urbano. 3. ed. Rio de Janeiro: Bertrand Brasil, 2007.

. Mudar a cidade: uma introdução crítica ao planejamento e à gestão urbanos. 8 . ed. Rio de Janeiro: Bertrand Brasil, 2013.

. O território: sobre espaço e poder, autonomia e desenvolvimento. In: CASTRO, I. E. de; GOMES, P. C. da C.; CORRÊA, R. L. (Org.). Geografia: conceitos e temas. 3. ed. Rio de Janeiro: Bertrand Brasil, p. 77-116, 2001.

SPOSITO, M. E. B. Novas formas comerciais e redefinição da centralidade intraurbana. In:___ (Org.). Textos e contextos para a leitura geográfica de uma cidade média. Presidente Prudente: GAsPERR/FCT/UNESP, p. 235-254, 2001.

. Segregação socioespacial e centralidade urbana. In: VASCONCELOS, P. A.;

CORRÊA, R. L.; PINTAUDI, S. M. (Org.). A cidade contemporânea: segregação espacial. São Paulo: Contexto, 2013. p. 61-93.

VASCONCELOS, P. A. A aplicação do conceito de segregação residencial ao contexto brasileiro na longa duração. Cidades, Presidente Prudente, v. 1, n. 2, p. 259-274, 2004.

. Contribuição para o debate sobre o processo e formas socioespaciais.

In: VASCONCELOS, P. A.; CORRÊA, R. L.; PINTAUDI, S. M (Org.). A cidade contemporânea: segregação espacial. São Paulo: Contexto, p. 16-37, 2013.

VILLAÇA, F. Espaço intraurbano no Brasil. São Paulo: Studio Nobel/FAPESP, 2001.

WACQUANT, L. As duas faces do gueto. São Paulo: Boitempo, 2008.

WIRTH, W. J. Le ghetto. Grenoble: Presses Universitaires de Grenoble, 1980. 
